\title{
Selective ablation of cancer cells with low intensity pulsed ultrasound $\odot$
}

Cite as: Appl. Phys. Lett. 116, 013701 (2020); https://doi.org/10.1063/1.5128627

Submitted: 22 September 2019 . Accepted: 02 December 2019 . Published Online: 07 January 2020

David R. Mittelstein (D), Jian Ye, Erika F. Schibber (D), Ankita Roychoudhury, Leyre Troyas Martinez (D), M. Houman Fekrazad (D), Michael Ortiz (D), Peter P. Lee (D), Mikhail C. Shapiro (D), and Morteza Charib

\section{COLLECTIONS}

F This paper was selected as Featured
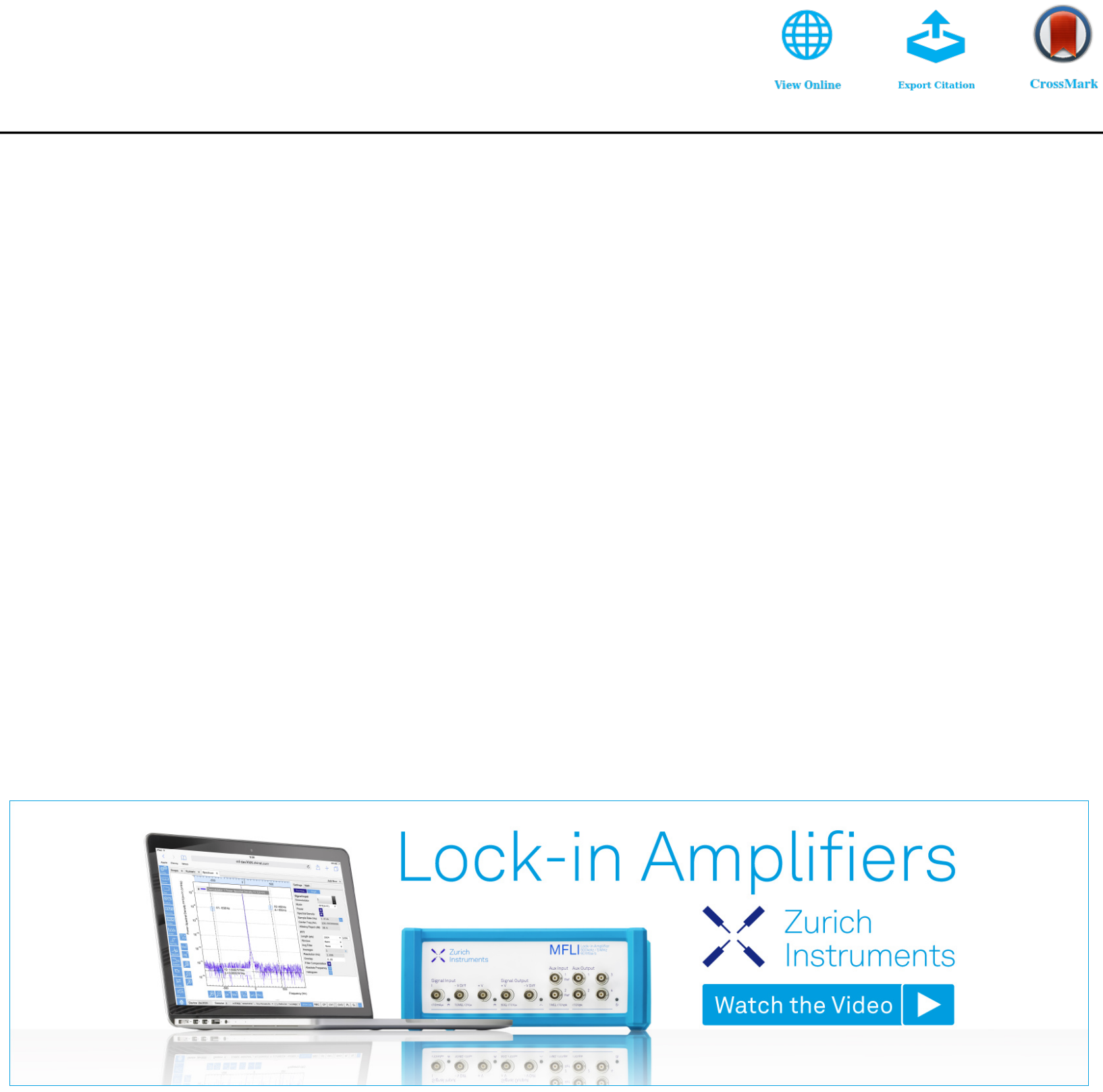


\title{
Selective ablation of cancer cells with low intensity pulsed ultrasound $\odot$
}

\author{
Cite as: Appl. Phys. Lett. 116, 013701 (2020); doi: 10.1063/1.5128627 \\ Submitted: 22 September 2019 - Accepted: 2 December 2019 . \\ Published Online: 7 January 2020
}

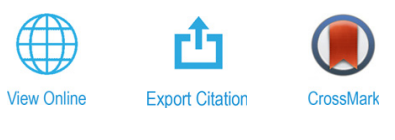

\begin{abstract}
David R. Mittelstein, ' (D) Jian Ye, ${ }^{2}$ Erika F. Schibber, ${ }^{1}$ (D) Ankita Roychoudhury, Leyre Troyas Martinez, M. Houman Fekrazad, ${ }^{2}$ (D) Michael Ortiz,' (D) Peter P. Lee, ${ }^{2}$ (D) Mikhail G. Shapiro, ${ }^{3, a)}$ (ID and Morteza Charib ${ }^{1, a)}$
\end{abstract}

\begin{abstract}
AFFILIATIONS
'Division of Engineering and Applied Sciences, California Institute of Technology, Pasadena, California 91125, USA

${ }^{2}$ Department of Immuno-Oncology, Beckman Research Institute, City of Hope, Duarte, California 91010, USA

${ }^{3}$ Division of Chemistry and Chemical Engineering, California Institute of Technology, Pasadena, California 91125, USA
\end{abstract}

\begin{abstract}
${ }^{a)}$ Authors to whom correspondence should be addressed: mikhail@caltech.edu and mgharib@its.caltech.edu
\end{abstract}

\begin{abstract}
Ultrasound can be focused into deep tissues with millimeter precision to perform noninvasive ablative therapy for diseases such as cancer. In most cases, this ablation uses high intensity ultrasound to deposit nonselective thermal or mechanical energy at the ultrasound focus, damaging both healthy bystander tissue and cancer cells. Here, we describe an alternative low intensity $\left(\mathrm{I}_{\mathrm{SPTA}}<5 \mathrm{~W} / \mathrm{cm}^{2}\right)$ pulsed ultrasound approach that leverages the distinct mechanical properties of neoplastic cells to achieve inherent cancer selectivity. We show that ultrasound applied at a frequency of $0.5-0.67 \mathrm{MHz}$ and a pulse duration of $>20 \mathrm{~ms}$ causes selective disruption of a panel of breast, colon, and leukemia cancer cell models in suspension without significantly damaging healthy immune or red blood cells. Mechanistic experiments reveal that the formation of acoustic standing waves and the emergence of cell-seeded cavitation lead to cytoskeletal disruption, expression of apoptotic markers, and cell death. The inherent selectivity of this low intensity pulsed ultrasound approach offers a potentially safer and thus more broadly applicable alternative to nonselective high intensity ultrasound ablation.
\end{abstract}

Published under license by AIP Publishing. https://doi.org/10.1063/1.5128627

High intensity focused ultrasound (HIFU) is a noninvasive therapeutic modality used clinically for tumor ablation. ${ }^{1-4}$ By producing local hyperthermia and destructive cavitation, ${ }^{5}$ HIFU induces cell lysis, increases chemotherapeutic uptake, ${ }^{3,6}$ and stimulates systemic antitumor immune responses. ${ }^{4,7}$ However, high intensity $\left(\mathrm{I}_{\mathrm{SPTA}}>100 \mathrm{~W} / \mathrm{cm}^{2}\right)$ and high pressure $(>10 \mathrm{MPa})$ focused ultrasound (FUS) indiscriminately destroys healthy tissue as well as tumors. ${ }^{8}$ Consequently, safely implementing HIFU often requires costly MRI targeting ${ }^{9}$ and is challenging in cancers near or invading into critical tissue. ${ }^{2}$

Several approaches aim to increase ultrasound's specificity. Molecularly targeted contrast agents, such as microbubbles, ${ }^{10}$ locally amplify ultrasound's disruptive effects but are challenging to deploy in tumors due to the agents' poor extravasation. ${ }^{11}$ An alternative approach involves low intensity pulsed ultrasound (LIPUS). Low intensity $\left(\mathrm{I}_{\text {SPTA }}<5 \mathrm{~W} / \mathrm{cm}^{2}\right)$ and low frequency $(<1 \mathrm{MHz})$ pulsed ultrasound, as defined in Ref. 12, produces mechanical effects without hyperthermia, resulting in neurostimulation, ${ }^{13}$ chemotherapy uptake, ${ }^{14}$ and bone repair. ${ }^{14,15}$ However, its ability to selectively ablate cancer cells has not been studied, and its mechanisms of action are not fully understood. ${ }^{16}$
Here, we test the hypothesis that biomechanical differences between cancerous and healthy cell types cause these cells to have different responses to LIPUS, allowing selective ablation of cancer cells with targeted ultrasound waveforms. This hypothesis is predicated on cancer cells' altered cellular/nuclear morphology, DNA content, nuclear-nucleolar volume ratios, cytoskeletal stiffness, and viscoelastic properties. ${ }^{17}$ In computational studies, these differences were predicted to result in the differential response of malignant cells to specific ultrasound parameters when compared to healthy cells. ${ }^{18}$ We use a cell suspension model to test this experimentally and examine the underlying acoustic and biophysical mechanisms.

To test the hypothesis that LIPUS can selectively ablate cancer cells, we applied LIPUS to suspensions of human K562 and U937 cancer lines and primary $\mathrm{T}$ cells isolated from human peripheral blood mononuclear cells (PBMCs), chosen as representative malignant and healthy cell types. Cell suspensions were placed in acoustically transparent-bottomed 24-well plates and insonated with a focused ultrasound transducer positioned in a water bath below [Fig. 1(a)]. We used pulsed ultrasound ( $10 \%$ duty cycle) with a peak negative pressure (PNP) of $<1.2 \mathrm{MPa}$ and $\mathrm{I}_{\mathrm{SPTA}}<5 \mathrm{~W} / \mathrm{cm}^{2}$. We confirmed that $60 \mathrm{~s}$ of 
(a) Cell Suspension
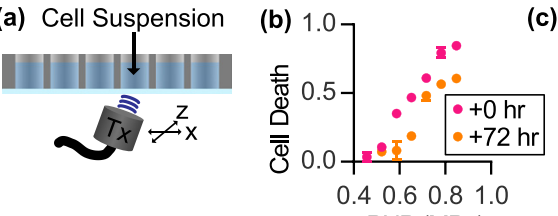

$\mathrm{PNP}(\mathrm{MPa})$
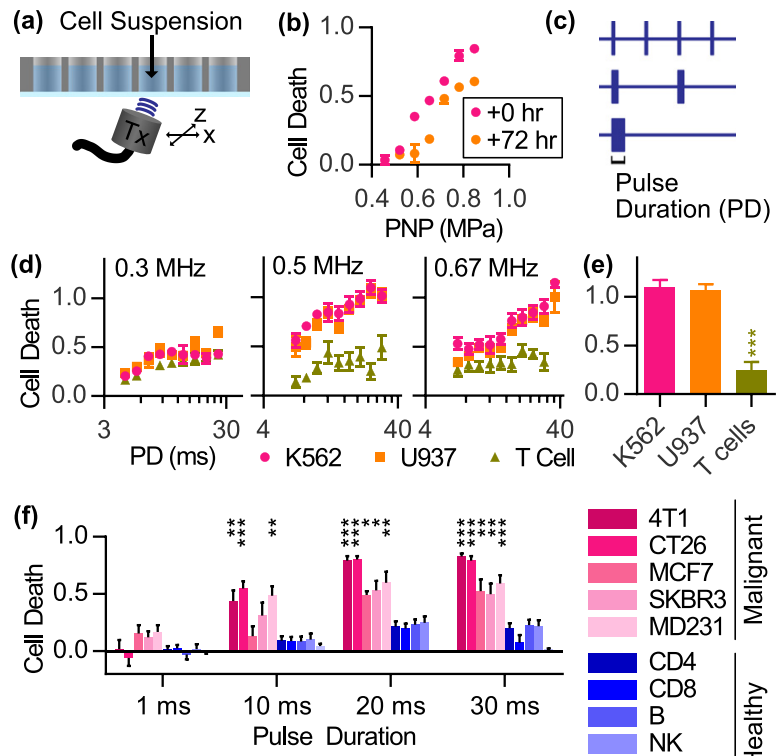

)
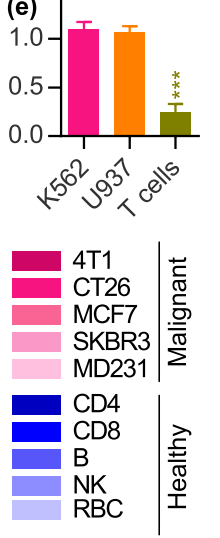

FIG. 1. Screening reveals ultrasound parameters that induce cancer-cell selective cytodisruption. (a) Schematic of the Mylar-bottom 24-well plate over the water bath containing the focused ultrasound transducer. (b) K562 cell death ( $\mathrm{N}=3$, error bars SEM) in response to $0.67 \mathrm{MHz}, 20 \mathrm{~ms} P D, 10 \%$ duty cycle, 60 s, LIPUS at various peak negative pressures (PNP). $0.7 \mathrm{MPa}$ PNP selected for future experiments. (c) Diagram depicting constant energy while sweeping PD. (d) $0.3(\mathrm{~N}=4), 0.5$ $(\mathrm{N}=9)$, and $0.67(\mathrm{~N}=9) \mathrm{MHz}$ LIPUS induces frequency-, PD-, and cell-dependent cytodisruption. (e) $0.5 \mathrm{MHz}, 20 \mathrm{~ms}$ PD LIPUS induces significantly less cell death $(\mathrm{N}=9, \mathrm{p}<0.001)$ on T cells compared to either K562 or U937. (f) $0.5 \mathrm{MHz}$ LIPUS induced cancer-selective cell death $(\mathrm{N}=9)$ in the mixed sample of healthy PBMC and cancer models (Table I), measured through cytometry. RBC death assessed using hemoglobin release. Significance indicated as the largest $p$-value from a 2-tailed t-test between each cancer and each healthy cell model $\left({ }^{*} p<0.05\right.$, ${ }^{* *} p<0.01$, and $\left.{ }^{* * *} p<0.001\right)$.

LIPUS at $0.67 \mathrm{MHz}$ and a $20 \mathrm{~ms}$ pulse duration (PD) induced significant and irreversible cytodisruption of K562 cells at PNP $>0.6 \mathrm{MPa}$, as measured with ethidium homodimer-1 (Ethd-1) uptake [Fig 1(b)]. Heating was always $<1{ }^{\circ} \mathrm{C}$ (Fig. Sup 1). For further experiments, we selected $0.7 \mathrm{MPa} \mathrm{PNP}$, which induced moderate cytodisruption. This pressure corresponds to a $1.63 \mathrm{~W} / \mathrm{cm}^{2} \mathrm{I}_{\mathrm{SPTA}}$ and $16.3 \mathrm{~W} / \mathrm{cm}^{2} \mathrm{I}_{\mathrm{SPTP}}$ at the $10 \%$ duty cycle. At the lowest frequency tested in this study, $0.3 \mathrm{MHz}$, this corresponds to a mechanical index of 1.3 , which is beneath the FDA safety limit of $1.9 .^{12}$ The lack of heating and the low mechanical index suggest that the ultrasound applied remains within the realm of LIPUS.

To test different pulsing patterns, PD and pulse repetition frequency were varied simultaneously to maintain a constant duty cycle [Fig. 1(c)]. This resulted in the application of the same total acoustic energy by each ultrasound waveform, allowing comparisons across frequencies and pulse durations. We swept PD from 2 to $40 \mathrm{~ms}$ with each of the 0.3, 0.5, and $0.67 \mathrm{MHz}$ transducers [Fig. 1(d)]. We observed that cytodisruption was highly dependent on frequency, PD, and cell type. $20 \mathrm{~ms} \mathrm{PD}$ and $0.5 \mathrm{MHz}$ maximized the selectivity with near complete cytodisruption for K562 and U937 and >80\% survival for T cells [Fig. 1(e)]. We found that cytodisruption increases with longer PD despite the same total energy applied. Next, we assessed a
TABLE I. Cell models tested at targeted parameters.

\begin{tabular}{lcc}
\hline \hline 4T1 & Mouse cell line & $\begin{array}{c}\text { Mammary gland, epithe- } \\
\text { lial (human breast cancer) } \\
\text { CT26 }\end{array}$ \\
Colon, fibroblast \\
(carcinoma) \\
SK-BR-3 & Human cell line & $\begin{array}{c}\text { Mammary gland, epithe- } \\
\text { lial (adenocarcinoma) }\end{array}$ \\
MDA-MB-231 & Human primary cells, & CD3+, CD4+ \\
CD4 & peripheral blood cells & CD3+, CD8+ \\
B & & CD3-, CD19+ \\
NK & Bovine primary cells & CD3-, CD19-, CD56+ \\
RBC & & Peripheral blood cells \\
\hline \hline
\end{tabular}

broader panel of cell types at $0.5 \mathrm{MHz}$, using cancer cells in coculture with PBMC (Table I). The cancer cell models showed significantly more cytodisruption than subpopulations within PBMC at $>10 \mathrm{~ms}$ PD [Fig. 1(f)]. Red blood cells (RBCs) exhibited virtually no disruption, as measured by hemoglobin leakage, under any condition.

To characterize LIPUS cytodisruption's biomolecular mechanisms, we evaluated CT-26 cells 2 days after 2 -min treatment with $0.5 \mathrm{MHz}$, $0.7 \mathrm{MPa}$ LIPUS with flow cytometry. At $>10 \mathrm{~ms} \mathrm{PD}$, increased cell death and apoptosis were observed ${ }^{19}$ [Fig. 2(a)]. Also, cells expressing calreticulin, a prophagocytic signal, ${ }^{20}$ increased, while proliferative marker Bcl-2 $2^{21}$ decreased [Fig. 2(b)]. The activation of apoptotic and phagocytic pathways may enhance LIPUS' effectiveness as an anticancer therapy by promoting the antitumor immune response.

To evaluate LIPUS' effect on the cytoskeleton, we performed confocal microscopy on CT-26 immediately after LIPUS. The actin cytoskeleton, stained with phalloidin, is qualitatively and quantitatively disrupted after insonation with $30 \mathrm{~ms}$ PD LIPUS. This agrees with the literature that states that LIPUS disrupts the cellular cytoskeleton. ${ }^{22}$ We demonstrate at $1 \mathrm{~ms}$ PD LIPUS, the cytoskeleton appears unchanged from the negative control [Fig. 2(c)].

Next, we investigated the physical mechanisms transducing LIPUS into cellular effects. The literature suggests that acoustic standing waves affect the mechanical forces experienced by cells. ${ }^{23}$ Such waves can result from interference of an incident ultrasound wave with its reflection, forming a spatially static pattern of pressure nodes and antinodes.

The pressure profile in acoustic 24 -well plates revealed a standing wave pattern near the water-air interface. To examine whether this plays a role in cytodisruption, we constructed an acoustically transparent cuvette, where standing waves could be optionally introduced using a reflector (RF) [Fig. 3(a)]. We found that cells insonated in the absence of standing waves $(0.67 \mathrm{MHz}, 100 \mathrm{~ms}$ PD) did not show significant cytodisruption, while cells treated in the presence of a reflector reproduced the cytodisruption observed in the 24 -well plate [Fig. 3(b)]. Doubling the PNP in the reflector-free configuration to match the maximal pressure at standing wave antinodes did not induce significant cytodisruption. This suggests that standing waves are mechanistically required for LIPUS cytodisruption.

Among other effects, acoustic pressure spatial gradients in standing waves give rise to acoustic radiation force that pushes cells toward pressure nodes. ${ }^{24}$ We tracked the motion of fluorescently 
(a)
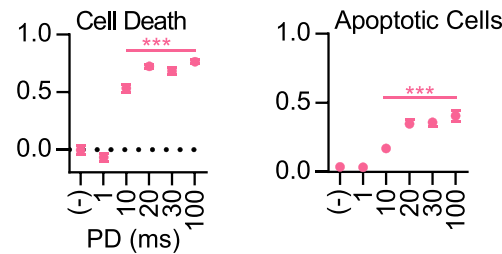

(b)

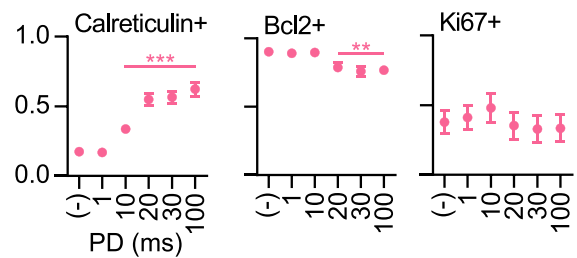

(c)

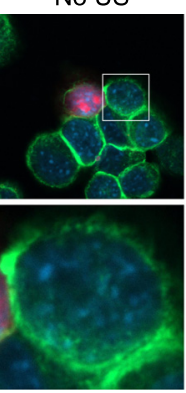

Dead Cell
$1 \mathrm{~ms} P D$

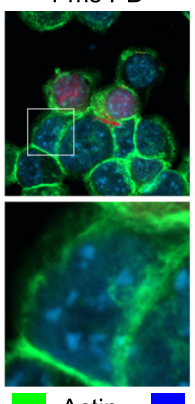

$30 \mathrm{~ms}$ PD

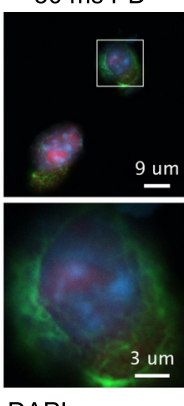

Actin Intensity

$2+$.

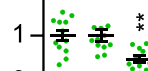

0.

(-) 130

$\mathrm{PD}(\mathrm{ms})$

FIG. 2. Ultrasound cytodisruption associated with apoptotic and prophagocytic pathways. (a) CT-26 cells assessed 2 days after LIPUS $(0.5 \mathrm{MHz}, 0.7 \mathrm{MPa} 20 \mathrm{~ms}$ PD, $10 \%$ DC, $2 \mathrm{~min}$ ). Fraction of surviving cells and apoptotic cells assessed using flow cytometry Ethd-1 vs Annexin V graphs (Fig. Sup 2). X-axis from no ultrasound (-) to $1-100 \mathrm{~ms}$ PD. Significantly increased cell death and apoptosis with $>10 \mathrm{~ms}$ PD LIPUS ( $N=12$, error bars SEM). (b) Increase in prophagocytic marker calreticulin $(\mathrm{N}=12)$ and decreased survival marker $\mathrm{Bcl} 2(\mathrm{~N}=8)$ but no change in proliferation marker Ki67 ( $\mathrm{N}=8)$ with $>20$ ms PD US. (b) Confocal microscopy of CT-26 cells immediately after LIPUS. $30 \mathrm{~ms}$ PD LIPUS disrupted the actin ring and significantly decreased actin stain intensity $(\mathrm{N}=12)\left({ }^{* *} \mathrm{p}<0.01\right.$ and $\left.{ }^{* * *} \mathrm{p}<0.001\right)$.

labeled K562 cells in response to continuous LIPUS in an imaging chamber and observed that $0.5 \mathrm{MHz}$ ultrasound in a standing wave configuration propelled cells toward the nodes [Fig. 3(c)]. A $100 \mathrm{~ms}$ $\mathrm{PD}$ was not sufficient for cells to aggregate at nodes, which happened after $\sim 1 \mathrm{~s}$ under continuous ultrasound.

Cavitation is a known mechanism for local amplification of acoustic pressure and cell killing. ${ }^{25}$ To examine its role in LIPUS cytodisruption, we measured the acoustic emissions of cells treated with LIPUS in the acoustic cuvette using a single-element passive cavitation detector orthogonally cofocused with the LIPUS transducer [Fig. 4(a)]. We measured the signature of inertial cavitation (emissions with a broad spectral content) and stable cavitation (harmonics of the transmitted frequency). As controls, we confirmed that no cavitation was measurable in degassed PBS cell buffer, while stable and inertial cavitation were detected from commercial Definity microbubbles, which were suspended in the degassed Phosphate Buffered Saline (PBS) for consistency [Fig. 4(b)].

K562 cells generated both stable and inertial cavitation when exposed to $0.5 \mathrm{MHz}, 100 \mathrm{~ms}$ PD LIPUS in the presence of a reflector. The cavitation magnitude increased during the LIPUS pulse with an

(a)
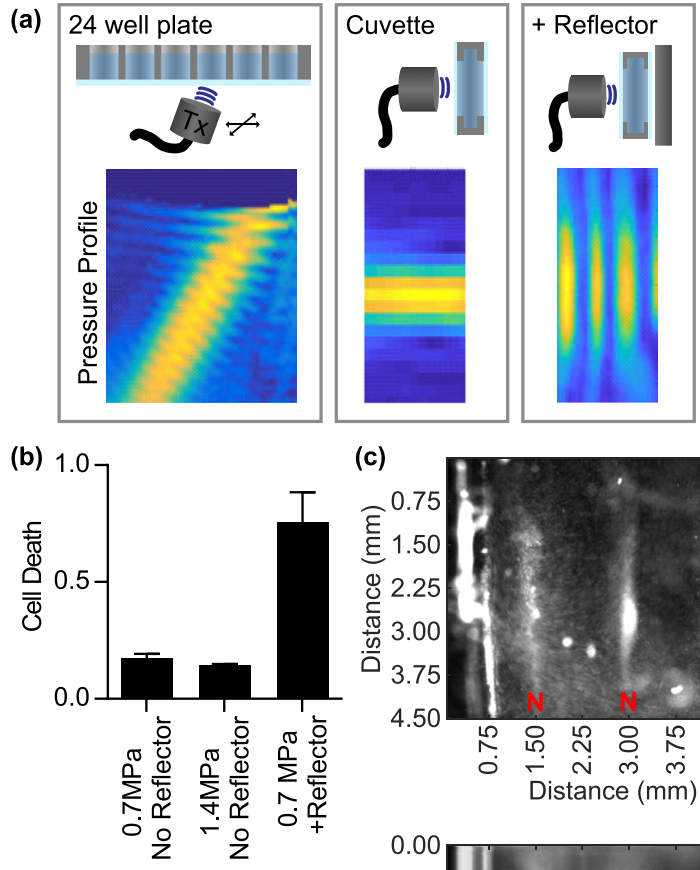

(c)
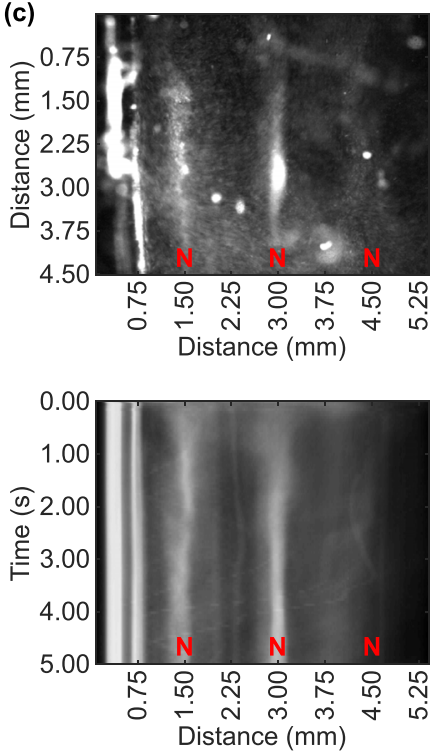

FIG. 3. Standing waves required for LIPUS cytodisruptive effect. (a) Schematics of experimental setups with pressure field measurements. Standing waves present in a 24-well plate, but not in the acoustic cuvette unless a metal reflector is introduced. (b) $0.67 \mathrm{MHz}, 100 \mathrm{~ms}$ PD, $0.7 \mathrm{MPa}$ LIPUS does not induce cell death in the acoustic cuvette without a reflector, even when doubling the pressure. However, when the reflector is added, cell death occurs as observed previously. (c) Fluorescence microscopy demonstrates that cells accelerate toward nodes $(\mathrm{N})$ in response to continuous $0.5 \mathrm{MHz}, 0.7 \mathrm{MPa}$ US. The upper image is still frame after $5 \mathrm{~s}$ of ultrasound, and the lower image represents the average of the y dimension (perpendicular to ultrasound) vs time. Cells achieve aggregation within $1 \mathrm{~s}$.

inflection point around $20 \mathrm{~ms}$ [Fig. 4(b)], a time scale similar to the PD needed for cytodisruption. No cavitation was seen without a reflector. Laser illumination of the cuvette revealed bubble formation in a standing wave pattern in response to long-PD ultrasound in the presence of the reflector [Fig. 4(d)].

The conditions resulting in LIPUS-induced cavitation in K562 cell suspensions correlate with those causing cytodisruption, with both requiring standing-waves and PD >20 ms [Fig. 4(c)]. However, cavitation is not sufficient for cytodisruption, since PBMCs, which are not strongly disrupted by tested LIPUS conditions, nevertheless, produced similar amounts of cavitation [Fig. 4(c)].

To determine which components of cell suspensions could be responsible for cavitation, we measured the acoustic signal from LIPUS-exposed solutions of cell-sized $10 \mu \mathrm{m}$ polystyrene beads and 
(a)

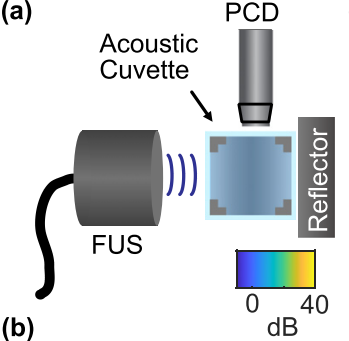

(b)
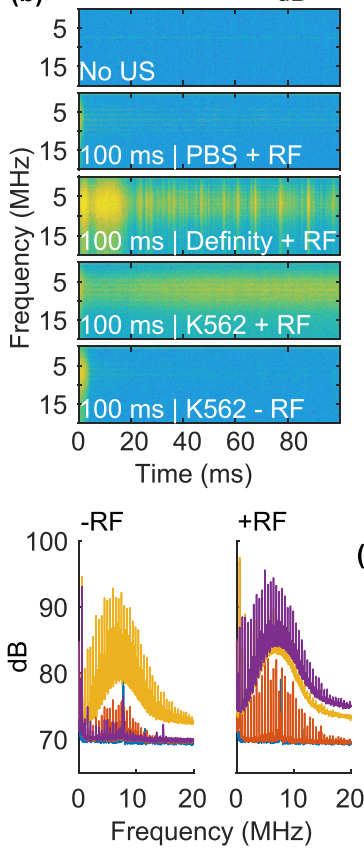

No US

$100 \mathrm{~ms}$ US | PBS

$100 \mathrm{~ms}$ US | Definity

100 ms US | K562 (c)

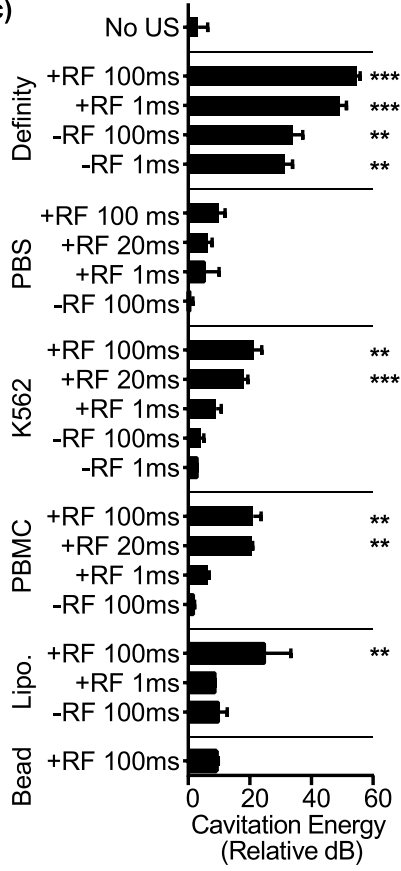

(d)
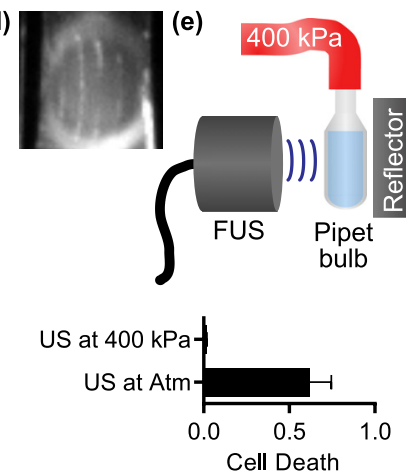

FIG. 4. Cell-mediated cavitation is mechanistically necessary for cytodisruption. (a) Schematic of passive cavitation detection setup using a $10 \mathrm{MHz}$ transducer orthogonally positioned to the FUS transducer. (b) Spectrogram of the scattered signal from $100 \mathrm{~ms}$ pulse of a $0.5 \mathrm{MHz}$ ultrasound transducer. Broadband signal of cavitation demonstrated with a Definity positive control. No cavitation in PBS, however, cavitation present in K562 suspensions only with a reflector. (c) Cavitation energy $\left(\int P^{2} d t\right)$ partially correlates with cytodisruption. Significant cavitation (compared to "No US," ** $\left.p<0.01,{ }^{* * *} p<0.001\right)$ observed with Definity, with K562/PBMC with reflector (RF) and $>20 \mathrm{~ms}$ PD, and with liposomes with RF and $100 \mathrm{~ms} P D$. Note: PBMC cells induce cavitation, though they are resistant to LIPUS cytodisruption. (d) $100 \mathrm{~ms}$ PD LIPUS with a reflector induces cavitation bubbles formed in the standing wave pattern in K562 sample. (e) Schematic of the pipet bulb pressurized to $400 \mathrm{kPa}$ to form a pressure chamber. At overpressure, which suppresses cavitation, LIPUS cytodisruption is suppressed.

liposomes. These liposomes were formed in the lab in degassed conditions to prevent gas core formation and degassed again prior to experiment. No cavitation was detected from the beads. However, degassed liposomes did produce cavitation, suggesting that cell's lipid contents may have a role in promoting cavitation [Fig. 4(c)].

Finally, to confirm that cavitation is necessary for cytodisruption, we suppressed cavitation using overpressure in an acoustically

transparent pressure-chamber ${ }^{26}$ comprising a plastic pipette bulb ${ }^{27}$ [Fig. 4(e)]. With the bulb pressurized to $400 \mathrm{kPa}$ above ambient pressure, there was an almost complete reduction of cytodisruption of K562 cells in the chamber by $100 \mathrm{~ms}$ PD LIPUS. This confirms that cavitation is mechanistically necessary.

To visualize LIPUS' effect on target cells, we imaged K562 cells in suspension under transmitted $2 \mathrm{~W}$ laser illumination using an ultrahigh speed camera. Laser light was only applied during image acquisition to prevent heating of the cells. Cells were floating between two acoustically transparent films near an acoustic reflector generating standing waves. We recorded a video at $5 \mathrm{Mfps}$ starting $100 \mathrm{~ms}$ after the beginning of insonation. We observed cells translating several microns along the axis of insonation at the ultrasound frequency, but not undergoing large-scale deformation [Figs. Sup 3 and Sup 4 (Multimedia view)]. This suggests that either that LIPUS' effect on the cell shape are on the nanoscale and thus not detectable in this imaging paradigm or involve deformation or displacement of subcellular organelles relative to the cytoplasm.

To investigate whether LIPUS cytodisruption occurs in cells embedded in solid media, we suspended K562 cells in agarose and acrylamide gels. We placed these gels in our acoustic cuvette with the reflector to generate standing waves [Fig. Sup 5(a)] and exposed them to ultrasound. Cell death in the LIPUS treated gels was assessed using Ethd-1 fluorescence and compared to untreated control gels [Fig. Sup 5(b)]. While statistically significant cytodisruption in agarose gels was observed, it was greatly attenuated compared to liquid suspensions [Fig. Sup 5(c)]. This suggests that either the mechanical rigidity or the translational motion restriction imposed by a solid extracellular medium inhibits LIPUS cell killing.

Our results demonstrate that specific parameters of low intensity pulsed ultrasound (LIPUS) can induce cancer cell-selective cytodisruption. In an in vitro model, LIPUS applied at $0.5 \mathrm{MHz}$ with a $20 \mathrm{~ms} \mathrm{PD}$ had the largest therapeutic margin in disrupting a diverse panel of cancer cells while leaving healthy blood and immune cells largely intact. While the acoustic intensity of the ultrasound is similar to that of diagnostic ultrasound, we found that cytodisruption only occurred with a pulse duration (PD) of greater than $10 \mathrm{~ms}$, while diagnostic ultrasound uses PD of about $10 \mu \mathrm{s}{ }^{12}$ Moreover, our experiments revealed that the formation of standing waves and the emergence of cavitation were necessary to disrupt cancer cells. However, the presence of cavitation, which was seeded by cells and enhanced by standing wave acoustic radiation force, was not sufficient to guarantee the disruption of any particular cell type. This is consistent with our finding that the most significant cytodisruption took place at $0.5-0.67 \mathrm{MHz}$ and not at $0.3 \mathrm{MHz}$ despite an expected increase in cavitation at lower frequency. This suggests that while cavitation may locally amplify the pressure supplied LIPUS, a given cell type's response to the resulting mechanical stress depends on its biophysical properties. This is consistent with the "oncotripsy" theory developed by Ortiz et al., ${ }^{18}$ which suggests that cells respond to ultrasound at different resonant frequencies and with different fatigue behaviors based on their distinct mechanical properties. ${ }^{18}$ Additional studies are needed to probe the biophysical underpinnings of this response.

Cancer-selective cytodisruption by LIPUS could fulfill the clinical need for safe noninvasive tumor ablation, complementing positional or molecular targeting approaches. Based on our results in suspension cell models, LIPUS applied within blood vessels could target blood 
cancer or circulating tumor cells. ${ }^{28}$ The needed standing waves could be generated by engineering the acoustic field of one or more array sources or leveraging endogenous reflective surfaces such as bones. In addition, the acoustic field may need to be sufficiently large to enable appropriate continuous exposure of cells during flow. In addition, our data indicating that LIPUS-disrupted cells show markers of apoptotic and immunogenic cell death (ICD) suggest that disruption of cancer cells in circulation could stimulate immune responses against solid tumors elsewhere and strengthen the effect of conventional chemotherapeutic regimens. ${ }^{29}$ Additional work is needed to extend this technology into the solid tumor context. While in our experiments cells in hydrogel phantoms responded weakly to LIPUS, this biochemical and mechanical context may not accurately represent the solid tumor milieu. In addition, even partial killing of solid tumor cells could be effective if it can precipitate an abscopal immune effect. Future cell monolayer, 3D culture, and finally in vivo studies are needed to test these hypotheses.

See the supplementary material for the materials and methods used in this manuscript as well as supplementary figures.

The authors thank Sangjin Yoo, Di Wu, Avinoam Bar-Zion, Dan Piraner, and Mohamad Abedi for helpful discussion. The authors also thank Sangjin Yoo for guidance with ultrasound LIPUS bioeffects in neuromodulation, Dan Piraner for cell culture and fluorescent protein transfection, Hunter Davis for input on HFR imaging optics, and $\mathrm{Di} \mathrm{Wu}$ for fluorescent cell tracking experiments. The authors also thank Michael R. Bailey for his assistance in designing the pipet bulb pressure chambers and Maayan Harel (www.maayanillustration.com) for the illustrations in this paper. Confocal microscopy experiments were performed at Caltech's Beckman Imaging Facility. This project was supported by Amgen CBEA 2017, 2018, and the Caltech/City of Hope collaborative grant 2019. A.R. and L.T.M. were supported by Caltech Summer Undergraduate Research Fellowships.

The authors declare no competing financial interest.

\section{REFERENCES}

${ }^{1}$ C. M. Tempany, N. J. McDannold, K. Hynynen, and F. A. Jolesz, Radiology 259(1), 39 (2011); Y. H. Hsiao, S. J. Kuo, H. D. Tsai, M. C. Chou, and G. P. Yeh, J. Cancer 7(3), 225 (2016)

${ }^{2}$ D. S. Hersh, A. J. Kim, J. A. Winkles, H. M. Eisenberg, G. F. Woodworth, and V. Frenkel, Neurosurgery 79(5), 643 (2016).

${ }^{3}$ M. Zhang, L. Liu, J. Wang, K. Lu, Y. Shu, R. Wang, and P. Liu, J. Ultrasound Med. 34(3), 435 (2015).

${ }^{4} J$. Unga and M. Hashida, Adv. Drug Delivery Rev. 72, 144 (2014).

${ }^{5}$ G. J. Van Leenders, H. P. Beerlage, E. T. Ruijter, J. J. de la Rosette, and C. A. van de Kaa, J. Clin. Pathol. 53(5), 391 (2000).

${ }^{6}$ O. Couture, J. Foley, N. F. Kassell, B. Larrat, and J.-F. Aubry, Transl. Cancer Res. 3(5), 494 (2014).

${ }^{7}$ Z. L. Xu, X. Q. Zhu, P. Lu, Q. Zhou, J. Zhang, and F. Wu, Ultrasound Med. Biol. 35(1), 50 (2009).

${ }^{8}$ J. F. Aubry, K. B. Pauly, C. Moonen, G. T. Haar, M. Ries, R. Salomir, S. Sokka, K. M. Sekins, Y. Shapira, F. Ye, H. Huff-Simonin, M. Eames, A. Hananel, N. Kassell, A. Napoli, J. H. Hwang, F. Wu, L. Zhang, A. Melzer, Y. S. Kim, and W. M. Gedroyc, J. Ther. Ultrasound 1, 13 (2013); J. P. McGahan, J. M. Brock, H. Tesluk, W. Z. Gu, P. Schneider, and P. D. Browning, J. Vasc. Interventional Radiol. 3(2), 291 (1992).
${ }^{9}$ G. Malietzis, L. Monzon, J. Hand, H. Wasan, E. Leen, M. Abel, A. Muhammad, P. Price, and P. Abel, Br. J. Radiol. 86(1024), 20130044 (2013).

${ }^{10}$ L. Y. Wang and S. S. Zheng, J. Zhejiang Univ., Sci., B 20(4), 291 (2019); A. Bar-Zion, A. Nourmahnad, D. R. Mittelstein, S. Yoo, D. Malounda, M. Abedi, A. Lee-Gosselin, D. Maresca, and M. G. Shapiro, preprint bioRxiv:620567 (2019).

11J. R. McLaughlan, S. Harput, R. H. Abou-Saleh, S. A. Peyman, S. Evans, and S. Freear, Ultrasound Med. Biol, 43(1), 346 (2017).

${ }^{12}$ T. R. Nelson, J. B. Fowlkes, J. S. Abramowicz, and C. C. Church, J. Ultrasound Med. 28(2), 139 (2009).

${ }^{13}$ P. P. Ye, J. R. Brown, and K. B. Pauly, Ultrasound Med. Biol. 42(7), 1512 (2016).

${ }^{14}$ A. K. Wood and C. M. Sehgal, Ultrasound Med. Biol. 41(4), 905 (2015).

${ }^{15}$ L. B. Feril, Jr., K. Tachibana, K. Ogawa, K. Yamaguchi, I. G. Solano, and Y. Irie, J. Med. Ultrason. 35(4), 153 (2008); G. J. Della Rocca, Indian J. Orthop. 43(2), 121 (2009).

${ }^{16}$ G. R. ter Haar and D. Robertson, Eur. Urol. 23(Suppl 1), 8 (1993); Z. Y. Shen, G. L. Xia, M. F. Wu, M. X. Shi, F. L. Qiang, E. Shen, and B. Hu, Exp. Biol. Med. 239(6), 747 (2014); M. Wiklund, Lab Chip 12(11), 2018 (2012).

${ }^{17}$ S. E. Cross, Y. S. Jin, J. Rao, and J. K. Gimzewski, Nat. Nanotechnol. 2(12), 780 (2007); S. K. Venkatesh, M. Yin, J. F. Glockner, N. Takahashi, P. A. Araoz, J. A. Talwalkar, and R. L. Ehman, Am. J. Roentgenol. 190(6), 1534 (2008); K. Pogoda, L. Chin, P. C. Georges, F. J. Byfield, R. Bucki, R. Kim, M. Weaver, R. G. Wells, C. Marcinkiewicz, and P. A. Janmey, New J. Phys. 16, 075002 (2014); M. Lekka, Bionanoscience 6, 65 (2016).

${ }^{18}$ S. Heyden and M. Ortiz, J. Mech. Phys. Solids 92, 164 (2016); Comput. Methods Appl. Mech. Eng. 314, 314 (2017).

${ }^{19}$ S. J. Martin, C. P. Reutelingsperger, A. J. McGahon, J. A. Rader, R. C. van Schie, D. M. LaFace, and D. R. Green, J. Exp. Med. 182(5), 1545 (1995).

${ }^{20}$ R. Osman, P. Tacnet-Delorme, J. P. Kleman, A. Millet, and P. Frachet, Front. Immunol. 8, 1034 (2017).

${ }^{21}$ A. C. Tsamandas, D. Kardamakis, P. Tsiamalos, A. Liava, V. Tzelepi, V. Vassiliou, T. Petsas, K. Vagenas, V. Zolota, and C. D. Scopa, Anticancer Res. 29(2), 703 (2009).

${ }^{22}$ S. Noriega, G. Hasanova, and A. Subramanian, Cells Tissues Organs 197(1), 14 (2013); M. Samandari, K. Abrinia, M. Mokhtari-Dizaji, and A. Tamayol, J. Biomech. 60, 39 (2017).

${ }^{23}$ D. Carugo, D. N. Ankrett, P. Glynne-Jones, L. Capretto, R. J. Boltryk, X. Zhang, P. A. Townsend, and M. Hill, Biomicrofluidics 5(4), 44108 (2011); J. J. Leskinen and K. Hynynen, Ultrasound Med. Biol. 38(5), 777 (2012).

${ }^{24}$ Y. Qiu, H. Wang, C. E. Demore, D. A. Hughes, P. Glynne-Jones, S. Gebhardt, A. Bolhovitins, R. Poltarjonoks, K. Weijer, A. Schonecker, M. Hill, and S. Cochran, Sensors (Basel) 14(8), 14806 (2014).

${ }^{25}$ J. H. Hwang, J. Tu, A. A. Brayman, T. J. Matula, and L. A. Crum, Ultrasound Med. Biol. 32(10), 1611 (2006).

${ }^{26}$ M. R. Bailey, L. N. Couret, O. A. Sapozhnikov, V. A. Khokhlova, G. ter Haar, S. Vaezy, X. Shi, R. Martin, and L. A. Crum, Ultrasound Med. Biol. 27(5), 695 (2001).

${ }^{27}$ J. C. Williams, Jr., M. A. Stonehill, K. Colmenares, A. P. Evan, S. P. Andreoli, R. O. Cleveland, M. R. Bailey, L. A. Crum, and J. A. McAteer, Ultrasound Med. Biol. 25(3), 473 (1999); O. A. Sapozhnikov, V. A. Khokhlova, M. R. Bailey, J. C. Williams, Jr., J. A. McAteer, R. O. Cleveland, and L. A. Crum, J. Acoust. Soc. Am. 112(3 Pt 1), 1183 (2002).

${ }^{28}$ C. Paoletti, Y. Li, M. C. Muniz, K. M. Kidwell, K. Aung, D. G. Thomas, M. E. Brown, V. G. Abramson, W. J. Irvin, Jr., N. U. Lin, M. C. Liu, R. Nanda, J. R. Nangia, A. M. Storniolo, T. A. Traina, C. Vaklavas, C. H. Van Poznak, A. C. Wolff, A. Forero-Torres, D. F. Hayes, and Consortium Translational Breast Cancer Research, Clin. Cancer Res. 21(12), 2771 (2015).

${ }^{29}$ L. Apetoh, F. Ghiringhelli, A. Tesniere, M. Obeid, C. Ortiz, A. Criollo, G. Mignot, M. C. Maiuri, E. Ullrich, P. Saulnier, H. Yang, S. Amigorena, B. Ryffel, F. J. Barrat, P. Saftig, F. Levi, R. Lidereau, C. Nogues, J. P. Mira, A. Chompret, V. Joulin, F. Clavel-Chapelon, J. Bourhis, F. Andre, S. Delaloge, T. Tursz, G. Kroemer, and L. Zitvogel, Nat. Med. 13(9), 1050 (2007). 